\title{
Pengembangan Buku Panduan Praktik Produksi Besar Pada Mata Kuliah Pengembangan Media Video Di Prodi Teknologi Pendidikan Universitas Negeri Jakarta
}

\author{
Muhammad Ergi Revian, ${ }^{\circledR}$ RA Murti Kusuma Wirasti ${ }^{2}$, Kunto Imbar Nursetyo ${ }^{2}$ \\ ${ }^{1}$ Universitas Negeri Jakarta, Jakarta, Indonesia. \\ ${ }^{2}$ Universitas Negeri Jakarta, Jakarta, Indonesia. \\ ${ }^{3}$ Universitas Negeri Jakarta, Jakarta, Indonesia. \\ DOI: https://doi.org/10.21009/JPI.031.04
}

\begin{tabular}{l}
\hline Article History \\
\hline Received : 2020 \\
Accepted : 2020 \\
Published : 2020 \\
\hline Keywords \\
\hline Keywords 1; Persepsi 2; \\
P-learning 3; Theory \\
Accpetance Model \\
4; Pemanfaatan \\
5.Pengelolaan Pusat \\
Sumber Belajar \\
\hline
\end{tabular}

\begin{abstract}
Penelitian pengembangan ini bertujuan untuk menghasilkan produk media berupa buku panduan produksi besar pada mata kuliah Penggembangan Media Video di Program Studi Teknologi Pendidikan Universitas Negeri Jakarta berbentuk buku elektronik dengan format EPUB. Penelitian pengembangan ini menggunakan model pengembangan Rowntree yang mempunyai tiga tahapan besar yaitu tahap perencanaan, tahap persiapan penulisan serta tahap penulisan dan penyuntingan. Tahapan evaluasi yang digunakan pada penelitian pengembangan ini yaitu tahap expert review, face-toface tryouts, dan field trials. Evaluasi melibatkan 1 orang ahli materi, 1 orang ahli media, dan 20 mahasiswa pengguna. Nilai rata-rata yang diperoleh dari tahap expert review oleh ahli materi adalah 3,4 dan menunjukan kategori sangat baik. Nilai rata-rata yang diperoleh dari tahap expert review oleh ahli media adalah 3,2 dan menunjukan kategori baik. Pada tahap face-to-face diperoleh nilai 3,4 dan menunjukan kategori sangat baik. Kemudian pada tahap field trials memperoleh nilai 3,3 yang menunjukan kategori sangat baik. Secara keseluruhan panduan ini sangat baik dan dapat digunakan untuk memandu mahasiswa dalam melakukan praktik produksi besar pada mata kuliah Pengembangan Media Video dengan baik dan benar.
\end{abstract}

\begin{abstract}
The research development aims to produce a guidebook of big production for development of video media course at Educational Technology Study Program, Universitas Negeri Jakarta in the form of ebooks in EPUB format. This development is referring to Rowntree's model that consists of three major stages; planning; preparation of writing; writing and editing. The evaluation on this development research was conducted through expert review, face-to-face trials, and field trials. The evaluation involving one subject matter expert, one media expert, and twenty student users. The average value obtained from the expert review by the subject matter experts was 3.4 overall excellent categories. The average value obtained from the expert review stage by the media expert was 3.2 overall good categories. In face-to-face tryouts, obtained the average score 3.4 overall guidance is excellent category. At the field trials obtained the average score 3.3 which signifies the overall guidance is excellent and can be be used to guide students in big production practice in development of Media Video course.
\end{abstract}

\footnotetext{
Corresponding author : Muhammad Ergi Revian

Adress: Universitas Negeri Jakarta

(C) 2020 Universitas Negeri Jakarta

Jakata, Indonesia

E-mail: ergi.muhammad14@gmail.com
} 


\section{PENDAHULUAN}

Media adalah perangkat penyajian pesan yang dapat menyajikan atau mengirim pesan antara pengirim pesan ke penerima pesan. Isi dari pesan tersebut memiliki arti dan tujuan yang beragam tergantung dari wujud fisik

Terdapat berbagai jenis media pembelajaran, salah satunya adalah video pembelajaran. Video adalah alat yang dapat menyajikan informasi, memaparkan proses, menjelaskan konsep-konsep yang rumit, mengajarkan keterampilan, menyingkat atau memperlambat waktu dan mempengaruhi sikap. Media video pembelajaran adalah media yang digunakan dalam proses pembelajaran yang dapat ditangkap oleh indera mata yang berisi konsep-konsep atau materi kompleks yang dikonversi menjadi menarik danmudah dipahami sehingga dapat mempersingkat proses belajar dan mempengaruhi sikap.

Dalam membuat sebuah video pembelajaran, dibutuhkan banyak crew dengan keterampilan dan pengetahuan dalam berbagai bidang yang menyangkut dengan proses produksi video yaitu konsep video yang diatur oleh sutradara, kemampuan menyusun skrip atau naskah oleh script writer, storyboard, sinematografi, peralatan produksi, dan pasca produksi dan sebagainya. Keterampilan atau keahlian tersebut perlu diperhatikan oleh crew sesuai dengan peran nya masing - masing.

Keterampilan dalam pembuatan video pembelajaran juga menjadi kompetensi yang harus dimiliki oleh beberapa lulusan perguruan tinggi. Salah satunya adalah lulusan dari Program Studi Teknologi Pendidikan Universitas Negeri Jakarta (UNJ). Program studi Teknologi Pendidikan UNJ mempunyai dua konsentrasi yaitu Teknologi Kinerja dan Perancang Pembelajaran. Perancang pembelajaran mempunyai kompetensi untuk memanfaatkan sumber sumber belajar yang bisa digunakan untuk menunjang proses pembelajaran, salah satunya adalah video pembelajaran. Video pembelajaran digunakan untuk memperjelas materi yang kompleks, video pembelajaran juga dapat memberikan nilai - nilai dan norma kepada peserta didik melalui cerita atau kisah yang di film kan.

Mata kuliah Pengembangan Media Video (PMV) merupakan mata kuliah yang tersedia dan dapat diambil oleh mahasiswa S1 Teknologi Pendidikan UNJ. Mata kuliah ini berbobot 4 SKS dan membina keahlian dalam bidang pengembangan program video dan televisi untuk pembelajaran; mulai dari pengembangan naskah sampai produksi suatu program video dan televisi. Penullisan naskah akan diarahkan pada naskah instruksional, dan naskah cerita pendek yang akan dinilai dan diseleksi oleh dosen pengampu yang akan digunakan sebagai naskah produksi yang dilakukan di lapangan. Sedangkan kegiatan produksi akan diarahkan pada pendekatan studio dan pendekatan lapangan. Mata kuliah ini memilki komposisi $40 \%$ teori dan $60 \%$ praktek. Pada saat jalannya perkuliahan metode yang digunakan adalah diskusi dan presentasi menggunakan powerpoint dengan referensi menggunakan video youtube dan beberapa penjelasan singkat mengenai praktik tugas akhir. Pelaksanaan tugas akhir atau praktik produksi tidak bisa didampingi oleh dosen pengampu yang menyebabkan mahasiswa kurang mengetahui proses dalam pembuatan video pembelajaran.

Antusias belajar dari individu mahasiswa dalam praktik pembuatan video kurang berminat karena kekurangan sumber informasi dalam proses produksi besar. Kemudian mahasiswa sering lupa terhadap langkah - langkah yang telah dijelaskan pada saat perkuliahan, dari hal tersebut mahasiswa kemudian bertanya kepada dosen pengampu, mencari sumber dari internet dan bertanya ke beberapa senior mereka. Kemampuan individu dalam membuat naskah video pembelajaran juga masih kurang karena sedikitnya informasi mengenai penyusunan naskah film.

Berdasarkan definisi Teknologi Pendidikan (TP) menurut Association for Educational Communication and Technology (AECT) tahun 2004, yaitu:

Educational Technology is the study and ethical practice of facilitating learning and improving performance bycreating, using, and managing appropriate technological processes and resource 
Sesuai dengan definisi tersebut, Teknologi Pendidikan memfasilitasi pembelajaran dengan memecahkan masalah belajar melalui intervensi yang ditawarkan yaitu kawasan penciptaan, penggunaan, dan pengaturan proses dan sumber daya teknologi untuk memfasilitasi pembelajaran guna meningkatkan kinerja.

Berdasarkan analisis masalah dan definisi TP dalam memecahkan masalah belajar. Peneliti melakukan penelitian pengembangan buku panduan elektronik untuk memfasilitasi mahasiswa dalam melakukan praktik produksi besar mata kuliah PMV. Panduan ini berfungsi sebagai pedoman dalam praktik produksi video pembelajaran pada mata kuliah Pengembangan Media Video yang berisikan tentang proses produksi video dalam mata kuliah ini yaitu menerapkan bahasa kamera, pembuatan naskah, jobdesk crew, produksi besar, dan evaluasi hasil produksi. Melalui pengembangan ini, diharapkan pelaksanaan praktik produksi dalam Pengembangan Media Video dapat berjalan dengan efektif dan efisien dengan mahasiswa yang aktif dalam praktik produksi tersebut.

\section{METODE}

Penelitian ini merupakan penelitian pengembangan yang menggunakan model pengembangan yang dikemukakan oleh Derek Rowntree. Model pengembangan Rowntree terdiri dari tiga tahapan besar yaitu: tahap perencanaan, tahap persiapan penulisan serta tahap penulisan dan penyuntingan.

Penelitian pengembangan ini dilaksanakan di program studi Teknologi Pendidikan, Fakultas Ilmu Pendidikan, Universitas Negeri Jakarta. Sasaran dari penelitian ini adalah mahasiswa yang sedang mengambil mata kuliah Pengembangan Media Video (PMV)

Pengembangan buku panduan elektronik ini melibatkan satu orang ahli materi, satu orang ahli media dan 20 mahasiswa pengguna. Teknik evaluasi yang digunakan adalah expert review, face-to-face tryouts dan field trials. Evaluasi dilakukan dengan cara menyebar kuesioner sebagai instrument penelitian. Kuesioner menggunakan skala 1-4 untuk menilai aspek konten/materi, fungsi panduan, karakteristik panduan, desain pesan panduan, dan format panduan.

Skor yang diperoleh kemukan menentukan kualitas buku panduan elektronik yang terkumpul menjadi data kuantitafif kemudian ditafsirkan menjadi data kualitatif dengan mengacu pada kualifikasi skor dengan rumus sebagai berikut:

$$
\text { Nilai Rata }- \text { Rata }=\quad \frac{\text { Jumlah Skor }}{\text { Jumlah Responden }}
$$

Untuk menilai kualitas buku panduan, interval kategori penilaian yang digunakan adalah sebagai berikut :

$4,00-3,25=$ sangat baik

$3,25-2,50=$ baik

$2,50-1,75=$ buruk

$1,75-1,00=$ sangat buruk

\section{HASIL DAN PEMBAHASAN}

Pengembangan buku panduan ini
menggunakan tiga tahap yang telah
dikemukakan oleh Rowntree, dengan
penjabaran tiap tahap sebagai berikut:

\section{A. Tahap Perencanaan}

Analisis karakter pengguna dilakukan untuk mendapatkan informasi tentang profil mahasiswa yang mengambil mata kuliah Pengembangan Media Video. Pada tahapan ini, pengembang mewawancarai beberapa mahasiswa program studi Teknologi Pendidikan Universitas Negeri Jakarta Angkatan 2016 dan 2017. Wawancara yang dilakukan merupakan wawancara tidak terstruktur. Berikut adalah hasil yang diperoleh yaitu profil karakter pengguna buku panduan:

Tabel 1 Profil Pengguna Panduan

\begin{tabular}{ll}
\hline Aspek & Deksripsi \\
\hline Demografi & $\bullet$ Mahasiswa TP \\
& Angkatan 2017 yang \\
& mengambil mata \\
& kuliah PMV berusia \\
& 20-23 tahun \\
\hline
\end{tabular}


Muhammad Ergi Revian | JPI/Vol.o3/No.o1/2020| H. 24 - 35

- Mayoritas mahasiswa adalah Digital Native

- Hambatan belajar dalam mata kuliah PMV adalah terbatasnya informasi yang disediakan mengenai alur produksi besar, teknik penulisan naskah, dan teknik dalam memproduksi video

\begin{tabular}{|c|c|}
\hline Motivasi & $\begin{array}{l}\text { - Motivasi pengguna } \\
\text { untuk menggunakan } \\
\text { panduan elektronik } \\
\text { karena mahasiswa } \\
\text { membutuhkan sumber } \\
\text { informasi berkaitan } \\
\text { dengan teknik } \\
\text { memproduksi media } \\
\text { video untuk } \\
\text { melakukan produksi } \\
\text { besar. Sumber } \\
\text { informasi tersebut } \\
\text { harus dapat diakses } \\
\text { dengan mudah } \\
\text { melalui gadget } \\
\text { mereka. } \\
\text { - Harapan mahasiswa } \\
\text { pada panduan } \\
\text { elektronik yang akan } \\
\text { dikembangkan yaitu: } \\
\text { - Materi tentang } \\
\text { penulisan naskah } \\
\text { video atau film } \\
\text { - Contoh teknik } \\
\text { pengambilan gambar } \\
\text { dalam film } \\
\text { - Tahapan-tahapan } \\
\text { dalam produksi } \\
\text { media video } \\
\text { - Informasi mengenai } \\
\text { kru produksi film }\end{array}$ \\
\hline Belajar & $\begin{array}{l}\text { - Kemampuan belajar } \\
\text { yang dimiliki } \\
\text { mahasiswa TP } \\
\text { Angkatan } 2017 \text { cukup } \\
\text { tinggi dan mandiri } \\
\text { dengan gaya belajar } \\
\text { yang beragam }\end{array}$ \\
\hline
\end{tabular}


Pengembang mengindentifikasikan keterampilan yang harus dicapai oleh mahasiswa dalam praktik produksi besar di mata kuliah PMV. Pengembang merumuskan tujuan pembelajaran umum dan tujuan pembelajaran khusus dari buku panduan elektronik sebagai berikut:

\section{Tujuan Umum}

Setelah mempelajari buku panduan ini, mahasiswa diharapkan dapat melaksanakan produksi besar dengan baik.

\section{Tujuan Khusus}

1) Mahasiswa dapat mengembangkan naskah program video

2) Mahasiswa dapat menguraikan Jobdesk kerabat kerja produksi

3) Mahasiswa dapat melakukan kegiatan produksi besar.

Penelitian ini menggunakan metode kuantitatif deskriptif, populasi yang digunakan pada penelitian ada mahasiswa Teknologi Pendidikan angkatan 2016 yang mengikuti mata kuliah Pengelolaan Pusat Sumber Belajar (PPSB), melalui instrument penelitian kuesioner yaitu persepsi mahasiswa terhadap pemanfaatan e-learning PPSB. Penelitian ini dilakukan pada periode bulan Juni-Agustus. Dari 81 kuesioner yang disebar, kuesioner yag kembali jumlahnya 78. Seluruh data dari hasil kuesioner dianalisis dengan menggunakan teknik analisis deskriptif.

Pengembang menyusun konten pada panduan dengan menggunakan berbagai sumber buku dan referensi artikel online dengan beberapa modifikasi agar sesuai dengan karakteristik pengguna.

Pengembang menyusun garis besar isi buku panduan produksi besar sebagai berikut:
Tabel 2 Garis Besar Isi Buku Panduan

\begin{tabular}{|c|c|c|c|}
\hline $\begin{array}{c}\text { Tujuan } \\
\text { Pembelajar } \\
\text { an Khusus }\end{array}$ & $\begin{array}{c}\text { Pokok } \\
\text { Bahasan }\end{array}$ & $\begin{array}{c}\text { Sub } \\
\text { Pokok } \\
\text { Bahasan }\end{array}$ & Pustaka \\
\hline $\begin{array}{l}\text { Melaksanaka } \\
\text { n pra- } \\
\text { produksi }\end{array}$ & $\begin{array}{l}\text { Melaksana } \\
\text { kan } \\
\text { kegiatan } \\
\text { pra } \\
\text { produksi }\end{array}$ & 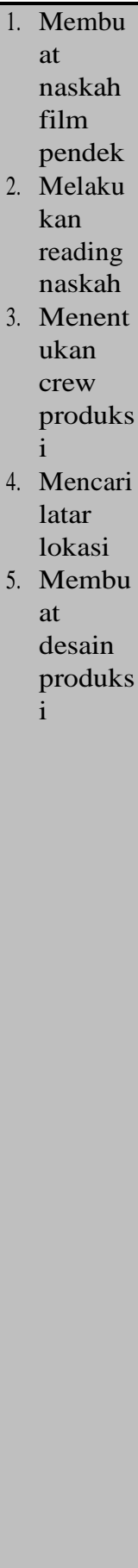 & 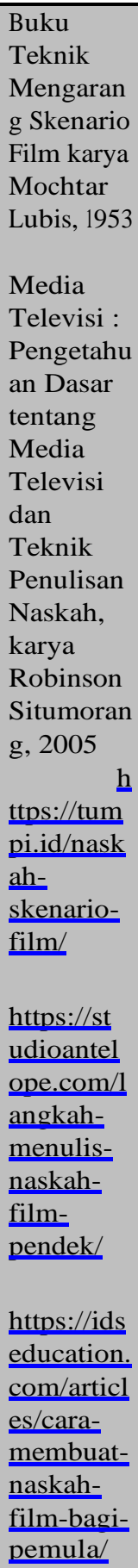 \\
\hline $\begin{array}{l}\text { Melaksanaka } \\
\text { n kegiatan } \\
\text { produksi }\end{array}$ & $\begin{array}{l}\text { Melakuka } \\
\mathrm{n} \text { tahapan } \\
\text { produksi }\end{array}$ & $\begin{array}{l}\text { 1. Jobdesk } \\
\text { crew } \\
\text { produks } \\
\text { i film } \\
\text { 2. Melaku } \\
\text { kan } \\
\text { evaluasi }\end{array}$ & $\begin{array}{l}\text { Buku } \\
\text { Videografi } \\
\text { dan } \\
\text { Sinematog } \\
\text { rafi } \\
\text { Praktis, } \\
\text { Karya }\end{array}$ \\
\hline
\end{tabular}


Muhammad Ergi Revian | JPI/Vol.o3/No.o1/2020| H. 24 - 35

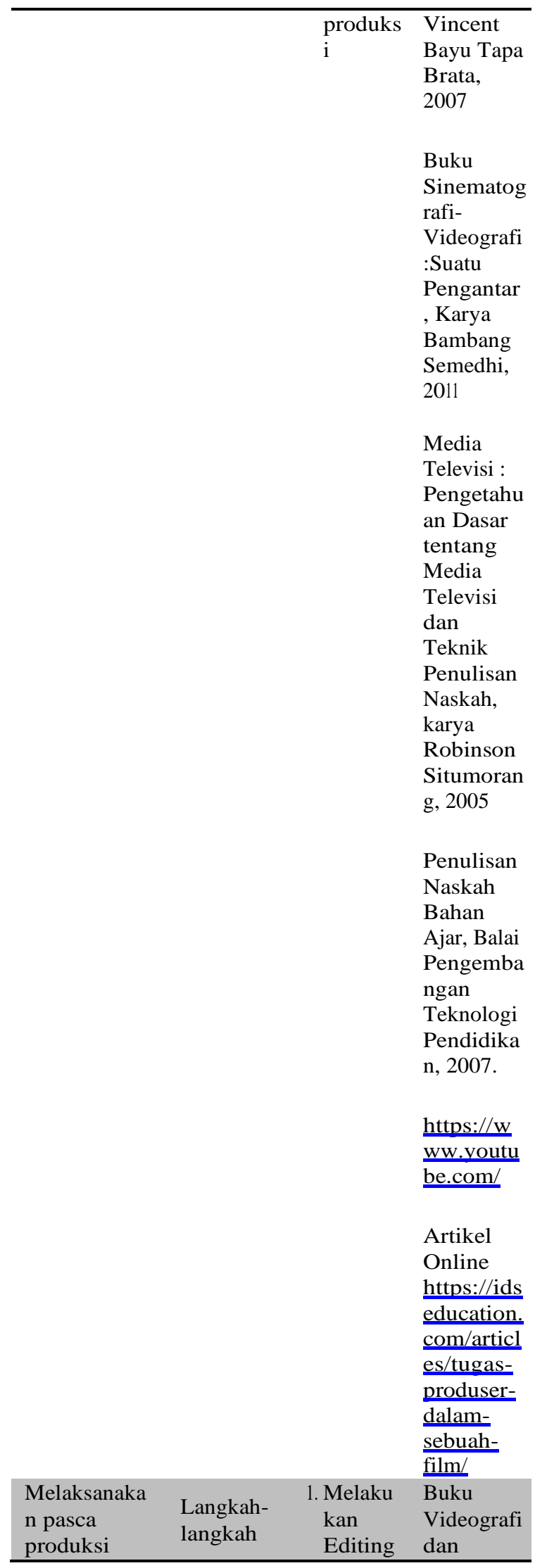

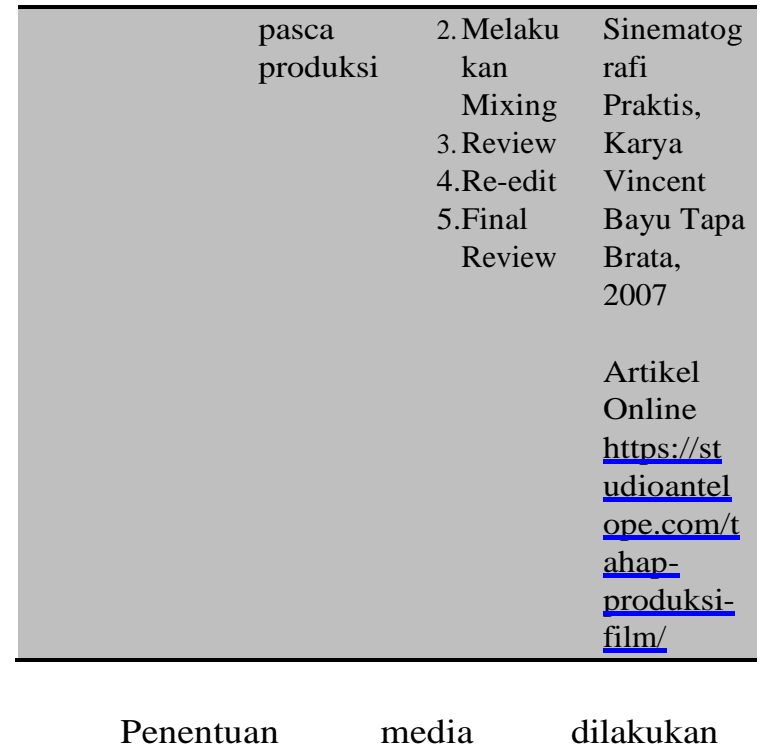

berdasarkan karakteristik pengguna yang mayoritas merupakan digital native sehingga media yang cocok berupa media elektronik berupa $E$-book dibanding media cetak. Platform yang digunakan dalam pembuatan buku panduan yaitu Kotobee Author dengan langkah-langkah sebagai berikut:

\section{Edit}

a. Memulai projek

Pengembang memulai dari awal dan memilih layout yang disediakan aplikasi yaitu Reflowable Layout untuk penulisan konten pada tiap bab dan Fixed Layout untuk bab alur produksi besar

b. Mulai menulis ebook

Pengembang mulai menulis konten buku panduan

c. Menambahkan media dan konten interaktif

- Fitur yang digunakan pengembang dalam menyusun media dan konten interaktif dalam membuat ebook yaitu : Images, Gallery, Link, dan Video.

- Dalam menentukan penempatan dan tampilan setiap media dan konten interaktif yang ditambahkan kedalam buku panduan, pengembang menggunakan posisi media di tengah layar pada tampilan ebook.

d. Mengatur chapter

Dalam buku panduan yang dikembangkan, pengembang membuat sepuluh bab yang terdapat di dalambuku panduan 
2. Kustomisasi

a. Kustomisasi tampilan aplikasi Pengembang menentukan warna khas dari tampilan ebook yaitu warna dasar jingga dan menampilkan cover pada saat membuka ebook.

b. Meninjau dan tes ebook dengan device and platfor emulation

Pengembang meninjau ulang ebook yang telah disusun dengan platform Apple dan Android

3. Ekspor projek

- Pengembang menentukan ekspor untuk buku panduan elektronik yang dikembangkan yaitu formatEPUB.

\section{Mengelola Ebook}

Pengembang menaruh file buku panduan melalui Google Drive dan librarty cloud milik Kotobee

\section{B. Tahap Persiapan Penulisan}

Pada tahap ini, Pengembang mempertimbangkan hal - hal yang dihadapi dalam proses pengembangan produk. Hambatan yang dihadapi oleh pengembang adalah keterbatasan waktu dalam mengembangkan produk dan keterbatasan pada CSS aplikasi pembuat E-Book. Pengembang membuat urutan jabaran materi berdasarkan garis besar isi buku panduan yang telah disusun dan tetapkan. Hasil dari tahap ini berupa Jabaran Materi. Pengembang berinisiatif untuk menambahkan aktivitas dan umpan balik pada panduan produksi besar berupa pembuatan desain produksi sebagai laporan kepada dosen pengampu mata kuliah. Lembar desain produksi dapat diakses melalui tautan Google Drive yang dimasukan kedalam buku panduan.

Contoh yang digunakan dalam buku panduan ini berupa gambar, Graphics Interchange Format (GIF), dan video mengenai teknik - teknik pengambilan gambar dan video dan contoh naskah video yang diakses melalui Google Drive. Kemudian, Penentuan grafis pada produk mengacu pada GBIM yang telah disusun dan diberikan contoh berupa gambar, video dan grafis yang mendukung penyampaian bahasan didalam buku panduan. Grafis yang digunakan dalam cover panduan menggunakan gaya flat design. Peletakan gambar dan grafis menggunakan acuan prinsip desain pesan dan tata letak buku elektronik

Pengembang membuat identifikasi peralatan yang dibutuhkan dalam pengembangan buku panduan elektronik, yaitu:

Tabel 3 Peralatan yang dibutuhkan

\begin{tabular}{|c|c|c|}
\hline $\begin{array}{c}\text { Nama } \\
\text { Alat/Bahan }\end{array}$ & Spesifikasi & Jumlah \\
\hline Laptop & $\begin{array}{l}\text { - Processor } \\
\text { Intel i5 } \\
\text { 8th } \\
\text { - RAM } 8 \text { GB } \\
\text { - VGA } \\
\text { - } 1 \text { TB } \\
\text { DRIVE } \\
\text { - MOUSE }\end{array}$ & 1 unit \\
\hline Software system & Windows 10 & 1 paket \\
\hline $\begin{array}{l}\text { Software ebook } \\
\text { author }\end{array}$ & $\begin{array}{l}\text { Kotobee } \\
\text { Author }\end{array}$ & 1 paket \\
\hline $\begin{array}{l}\text { Software ebook } \\
\text { reader }\end{array}$ & $\begin{array}{l}\text { Kotobee } \\
\text { Reader }\end{array}$ & 1 paket \\
\hline $\begin{array}{l}\text { Software photo } \\
\text { editing }\end{array}$ & $\begin{array}{l}\text { Adobe } \\
\text { Photoshop }\end{array}$ & 1 paket \\
\hline $\begin{array}{l}\text { Software digital } \\
\text { illustration }\end{array}$ & $\begin{array}{l}\text { Adobe } \\
\text { Illustrator }\end{array}$ & 1 paket \\
\hline Software browser & $\begin{array}{l}\text { Google } \\
\text { Chrome }\end{array}$ & 1 paket \\
\hline $\begin{array}{l}\text { Software } \\
\text { pengolah kata }\end{array}$ & $\begin{array}{l}\text { Microsoft } \\
\text { Word }\end{array}$ & 1 paket \\
\hline
\end{tabular}

\section{Tahap Penulisan dan Penyuntingan}

Pengembang menyusun draft berdasarkan garis besar isi buku panduan dan jabaran materi buku panduan yang telah dirancang. Pengembang membuat draft dan konten pada aplikasi pengolah kata Microsoft Word yang kemudian dipindahkan kedalam aplikasi pembuat E-Book. Berikut adalah susunan konten buku panduan:

1. Cover

2. Penulis

3. Daftar Isi

4. Kata Pengantar

5. Deskripsi Mata Kuliah

6. Alur Produksi

7. Bagian 1 : Pra Produksi

a) Membuat Naskah

b) Reading Naskah

c) Menentukan Crew Produksi 
d) Hunting Lokasi

e) Membuat Desain Produksi

8. Bagian 2 : Produksi

a) Jobdesk Lapangan Kru Produksi Film

b) Review Hasil Produksi

9. Bagian 3 : Pasca Produksi
a) Editing
b) Mixing
c) Review
d) Re-edit
e) Post production

10. Glosarium

11. Daftar Pustaka

Setelah menyusun draft, pengembang menambahkan materi konten berupa teks, gambar, GIF, video, hyperlink, dan ilustrasi yang telah dibuat sebelumnya. Berikut adalah cover dan konten media dalam buku panduan elektornik ini:

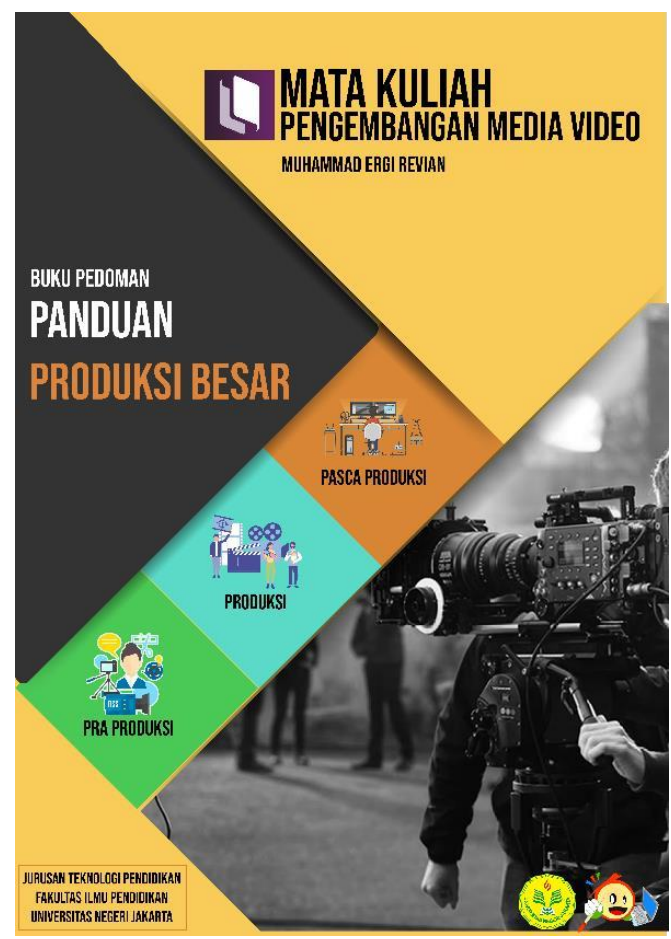

Gambar 1 Cover Buku Panduan

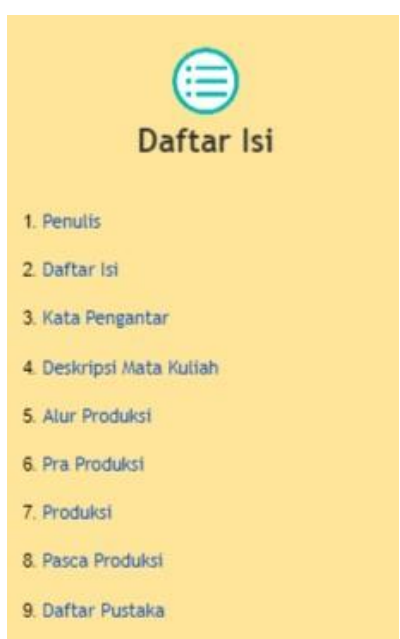

Gambar 2 daftar isi buku panduan

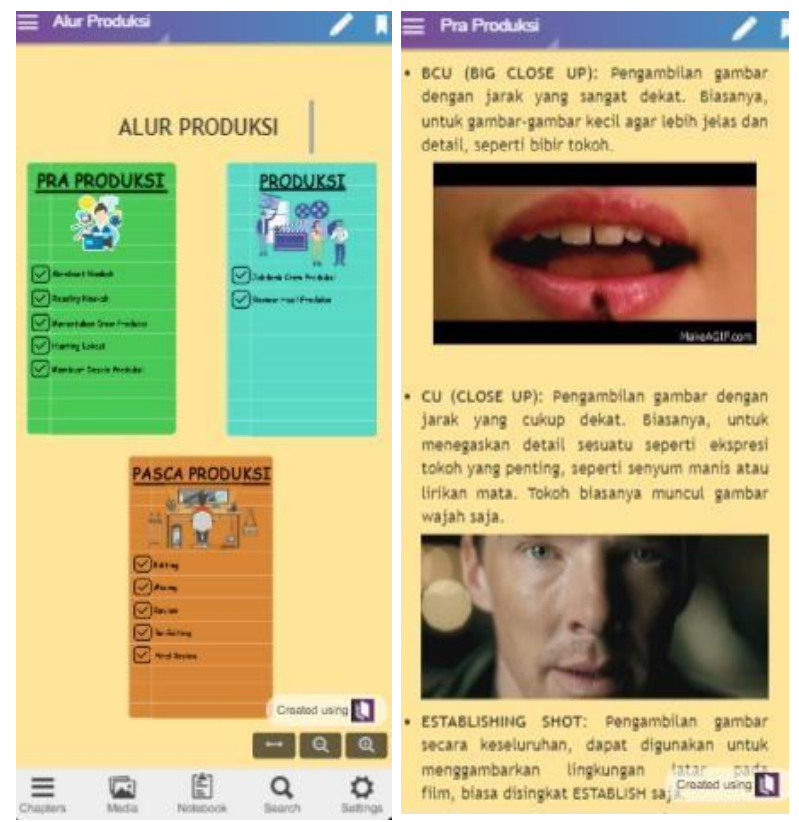

Gambar 3 Konten Buku Panduan

Kemudian pada tahap terakhir pengembang menguji coba dan memperbaiki panduan melalui expert review, face-to-face trials, dan field trials. Tahap expert review melibatkan ahli materi dan ahli media dengan hasil sebagai berikut:

Tabel 4 Rekapitulasi ahli

\begin{tabular}{lc}
\hline \multicolumn{1}{c}{ Responden } & Nilai Rata-Rata \\
\hline Ahli Materi & $\mathbf{3 , 4}$ \\
Ahli Media & $\mathbf{3 , 2}$ \\
Rata-rata & $\mathbf{3 , 3}$ \\
\hline Keseluruhan & \\
\hline
\end{tabular}


Muhammad Ergi Revian | JPI/Vol.o3/No.o1/2020| H. 24 - 35

Berdasarkan hasil perhitungan rata rata diatas, skor hasil keseluruhan yang dicapai produk yang dicapai adalah sangat baik, dengan keseluruhan nilai rata - rata sebesar 3,3. Panduan produksi besar yang dikembangkan memiliki kualitas yang sangat baik dalam aspek materi dan kualitas baik dalam aspek media. Berikut beberapa masukan dari tahap expert review:

Tabel 5 Masukan Para Ahli

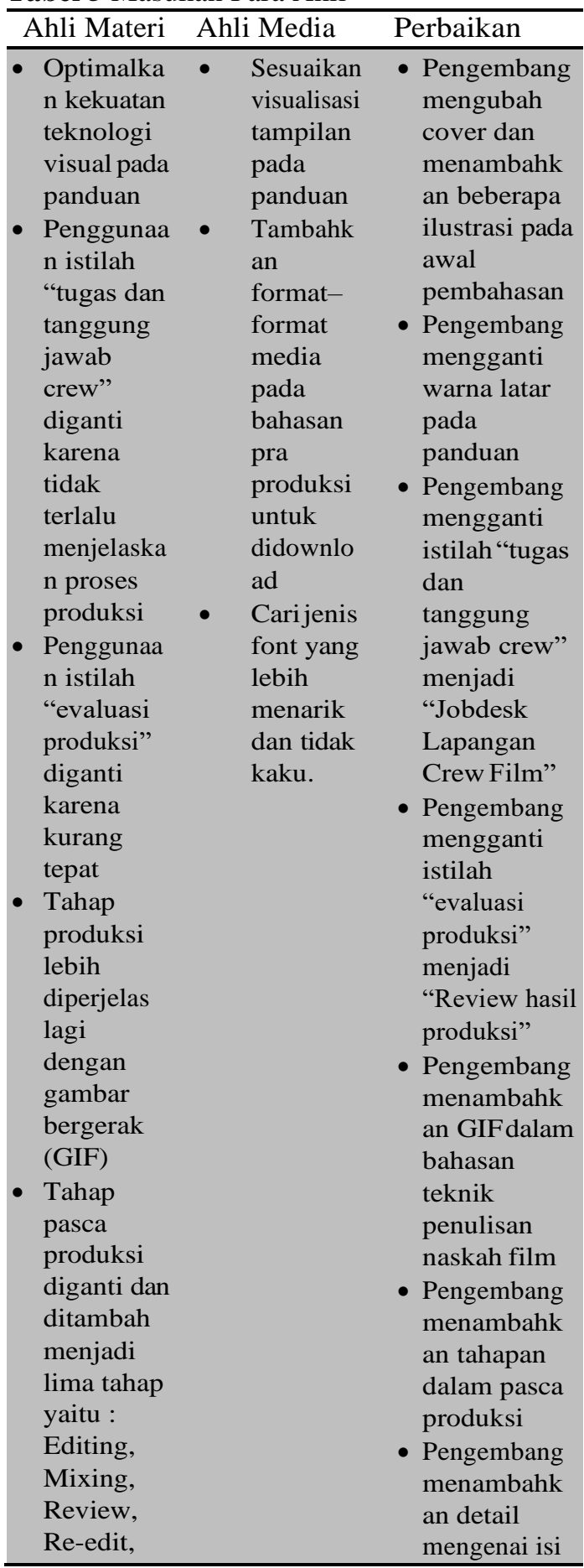

\begin{tabular}{ll}
\hline Final & desain \\
review & produksi \\
- Desain & director \\
produksi & treatment", \\
dibuat & Spesifikasi \\
lebih detail & editing, dan \\
per & list kru film \\
jobdesk & Pengembang \\
dari kru & menambahk \\
produksi & an tautan \\
& google drive \\
& untuk \\
& contoh \\
& naskah dan \\
& desain \\
& produksi \\
& Pengembang \\
& menambahk \\
& an video \\
& pada jobdesk \\
& DOP \\
& \\
\hline
\end{tabular}

Pada tahap face-to-face, pengembang mengujicobakan produk kepada tiga orang mahasiswa Teknologi Pendidikan Angkatan 2017 yang sedang mengambil mata kuliah PMV. Kegiatan ujicoba ini dilakukan pada 30 Desember 2019. Hasil dari face-to-face tersebut tersaji sebagai berikut:

Tabel 6 Rekapitulasi face-to-face

\begin{tabular}{lc}
\hline \multicolumn{1}{c}{ Responden } & $\begin{array}{c}\text { Nilai Rata - } \\
\text { rata }\end{array}$ \\
\hline Yosua Andika & 3.6 \\
Uli Afrilia Wahyu & 3.3 \\
Anugrah Gita Putra & 3.3 \\
$\begin{array}{l}\text { Rata-rata } \\
\text { keseluruhan }\end{array}$ & $\mathbf{3 . 4}$ \\
\hline
\end{tabular}

Dari hasil face to face tersebut, didapatkan nilai rata-rata sebesar 3.4 yang menunjukan bahwa panduan produksi besar sangat baik berdasarkan penilaian pengguna dan dapat membantu mahasiswa dalam melakukan produksi besar pada mata kuliah PMV. Berikut adalah saran yang diperoleh dari hasil face-to-face: 
Muhammad Ergi Revian | JPI/Vol.o3/No.o1/2020| H. 24 - 35

Tabel 7 Masukan Face-to-face

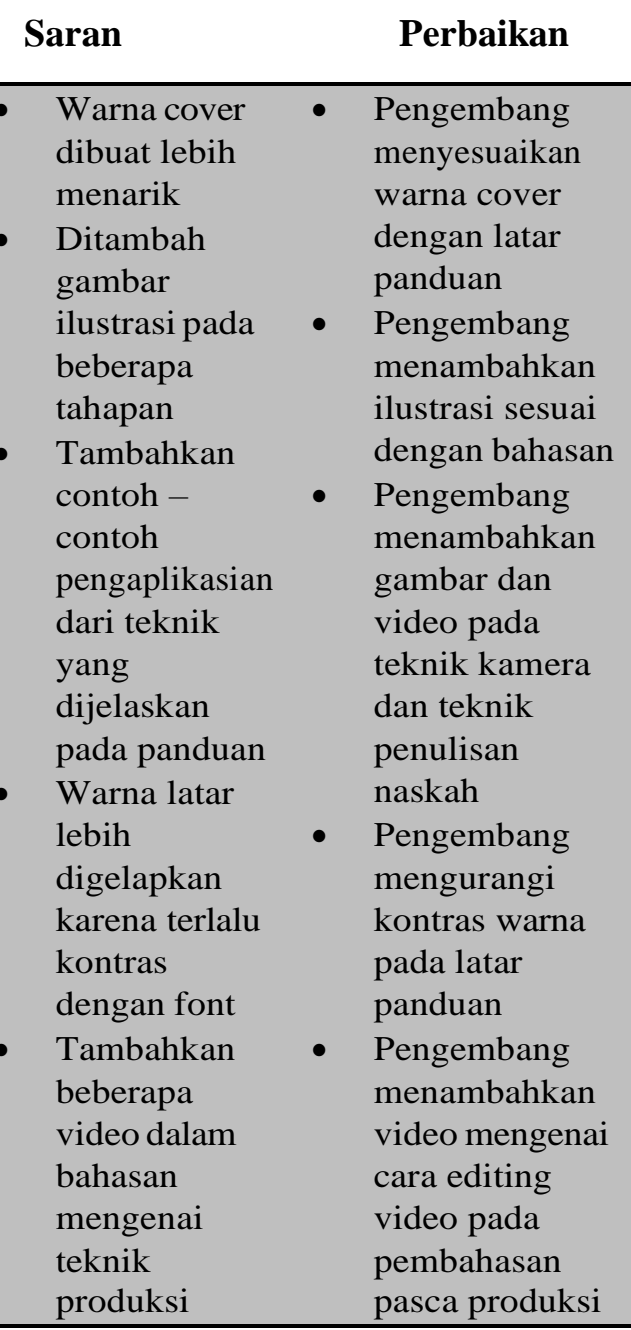

Pada tahap field trials, kuisioner dibagikan kepada 20 mahasiswa TP 2017. Tahap ini dilakukan pada tanggal 9 Januari 2020. Hasil dari field trials tersebut tersaji dalam rekapitulasi sebagai berikut :

Tabel 8 Rekapitulasi field trials

\begin{tabular}{cc}
\hline Responden & $\begin{array}{c}\text { Nilai Rata- } \\
\text { rata }\end{array}$ \\
\hline 1 & $\mathbf{3 , 2}$ \\
2 & $\mathbf{3 , 3}$ \\
$\mathbf{3}$ & $\mathbf{3 , 1}$ \\
$\mathbf{4}$ & $\mathbf{3 , 6}$ \\
$\mathbf{5}$ & $\mathbf{3 , 4}$ \\
$\mathbf{6}$ & $\mathbf{3 , 1}$ \\
$\mathbf{7}$ & $\mathbf{3 , 1}$ \\
$\mathbf{8}$ & $\mathbf{3 , 2}$ \\
$\mathbf{9}$ & $\mathbf{3 , 0}$ \\
$\mathbf{1 0}$ & $\mathbf{3 , 3}$ \\
11 & $\mathbf{3 , 2}$ \\
\hline
\end{tabular}

\begin{tabular}{|cc}
\hline 12 & $\mathbf{3 , 0}$ \\
13 & $\mathbf{3 , 1}$ \\
14 & $\mathbf{3 , 4}$ \\
15 & $\mathbf{3 , 1}$ \\
16 & $\mathbf{3 , 4}$ \\
17 & $\mathbf{3 , 1}$ \\
18 & $\mathbf{3 , 3}$ \\
19 & $\mathbf{3 , 4}$ \\
$\mathbf{2 0}$ & $\mathbf{3 , 3}$ \\
Rata-rata & $\mathbf{3 , 3}$ \\
\hline Keseluruhan & \\
\hline
\end{tabular}

Dari hasil field trial, nilai rata - rata yang didapatkan oleh produk sebesar 3,3 yang menunjukan bahwa panduan dinilai sangat baik dari sudut pandang pengguna untuk panduan produksi besar pada mata kuliah PMV. Berikut adalah saran yang diperoleh dari field trial:

a. Tambahkan desain untuk layout agar lebih menarik

b. font yang digunakan lebih besar lagi karena kurang terbaca

c. Penggunaan warna latar lebih disesuaikan agar lebih enak dipandang

d. gambar visual mengenai alur produksi ditambah lagi agar informasi yang disampaikan lengkap

e. Isi konten lebih diperbanyak lagi

\section{SIMPULAN}

Penelitian pengembangan ini menghasilkan produk media berupa panduan produksi besar pada mata kuliah Penggembangan Media Video di Program Studi Teknologi Pendidikan Universitas Negeri Jakarta berbentuk buku elektronik dengan format EPUB. Buku panduan ini dikembangkan berdasarkan masalah belajar yang dialami oleh mahasiswa pada mata kuliah PMV yaitu kurangnya informasi mengenai proses produksi besar, sehingga buku panduan ini dikembangkan untuk memberikan informasi dan pedoman dalam melaksanakan produksi besar. Pengembangan buku panduan produksi besar ini menggunakan model pengembangan produk yang dikemukakan oleh Rowntree. Model ini mencakup tiga tahapan yaitu tahap perencanaan, tahap penulisan dan tahap penyuntingan. 
Reviu ahli materi menyatakan bahwa Panduan Elektronik Produksi Besar ditinjau dari aspek materi dinilai sangat baik, dengan skor 3,4 dan bisa digunakan sebagai bahan ajar pada mata kuliah PMV

Reviu ahli media menyatakan bahwa Panduan Elektronik Produksi Besar ditinjau dari aspek media dinilai baik dengan skor 3,2 dan layak untuk digunakan. Uji coba pengguna tahap face to face melibatkan tiga orang mahasiswa Teknologi Pendidikan Angkatan 2017 menyatakan bahwa Panduan Elektronik Produksi Besar dinilai sangat baik dengan skor 3.4 dan bisa digunakan dalam mata kuliah PMV. Uji coba pengguna tahap Field Trials melibatkan 20 orang mahasiswa Teknologi Pendidikan Angkatan 2017 menyatakan bahwa Panduan Elektronik Produksi Besar dinilai sangat baik dengan skor 3,3 dan bisa digunakan dalam mata kuliah PMV.

Berdasarkan reviu dan uji coba yang telah dilakukan, maka dapat dinyatakan bahwa panduan produksi besar pada mata kuliah Pengembangan Media Video memiliki kualitas yang baik dan dapat digunakan untuk memfasilitasi mahasiswa dalam melakukan praktik produksi besar sesuai dengan langkah langkah produksi video.

\section{SARAN}

Pengembangan panduan ini tentunya masih memiliki kekurangan dan memerlukan perbaikan secara berkelanjutan agar dapat memfasilitasi mahasiswa dalam melakukan produksi besar. Oleh karena itu, terdapat beberapa saran pengembang, yaitu :

1. Bagi mahasiswa Teknologi Pendidikan yang mengambil mata kuliah PMV, agar menggunakan panduan produksi besar ini sebagai pedoman dan sumber informasi dalam melakukan produksi besar sesuai dengan alur produksi media video

2. Bagi dosen pengampu mata kuliah PMV, agar dapat menggunakan panduan produksi besar sebagai bahan ajar dalam perkuliahan

3. Bagi Mahasiswa Teknologi Pendidikan, dapat membuat penelitian lanjutan mengenai panduan yang membahas tentang teknik pengambilan gambar secara rinci bagi mahasiswa dalam produksi besar
PMV, karena masih banyak mahasiswa TP yang belum memahami teknik pengambilan gambar untuk produksi video.

4. Bagi pengembang media yang akan mengembangkan buku panduan elektronik, agar dapat menentukan aplikasi pembuat Ebook yang fleksibel dan sesuai dengan kemampuan pegembang. Disarankan pula agar menggali informasi mengenai bahasan panduan yang akan ditaruh dalam panduan. Selain itu, pertimbangkan waktu pengembangan agar hasil produk dapat

\section{UCAPAN TERIMA KASIH}

Terima kasih kepada Ibu RA Murti Kusuma W. dan Bapak Kunto Imbar Nursetyo yang telah memberikan bantuan dan bimbingan penulisan penelitian ini. Kepada pihak lain yang tidak bisa disebutkan satupersatu saya ucapkan terima kasih.

\section{DAFTAR PUSTAKA}

Alan Januszewski dan Michael Molenda. 2008 Educational Technology : A Definition With Commentary, London Routledge

Ali Imron. 1996. Belajar dan Pembelajaran, Jakarta : Dunas Pustaka Jaya

Benny A Pribady. 2008. Model Desain Pembelajaran, Jakarta: Dian Rakyat

B.P, Sitepu. 2012. Penulisan Buku Teks Pelajaran. Bandung: PT Remaja Rosdakarya

Cecep Kustandi dan Bambang Sutjipto. 2013. Media Pembelajaran Manual dan Digital Edisi Kedua. Bogor: Ghalia Indonesia

Derek Rowntree. 1994. Preparing Materials For Open, Distance, and Flexible Learning. London: Kogan Page

Dewi S. Prawiradilaga. 2009. Prinsip Desain Pembelajaran, Jakarta : KENCANA, 
Eveline Siregar dan Hartini Nara. 2010. Teori Belajar dan Pembelajaran, Bogor : Ghalia Indonesia

Iswara, V., Sitepu, B., \& Suprayekti, S. 2018. Pengembangan Buku Panduan "Urinalisis" di Laboratorium. Jurnal Pembelajaran Inovatif di akses pada : https://doi.org/https://doi.org/10.210 09/JPI.011.08 Hari Kamis, 12 September 2019 pukul 20.00

Kadek Urip Kurniawan. 2016. "Pengembangan Multimedia Ular Tangga Model Hannafin dan Peck Untuk Meningkatkan Hasil Belajar Mata Pelajaran IPA Pada Siswa KelasMenengah Kelas VIII Semester Genap di SMP Negeri 6 Singaraja". Vol. 5 No. 2,

Kent. L. Gustafon dan Robert Maribe Bracnh. 2002. Survey of Instructional Development Models, Educational Resources Information Center

Miarso, Yusuf. 2011. Menyemai Benih Teknologi Pendidikan. Jakarta: Kencana.

Mochtar Lubis. 1953. Tehnik Mengarang Skenario Film, Jakarta: Balai Pustaka

Mudai, Yudhi. 1999. Penulisan Buku Teks Pelajaran. Bandung: PT. Remaja Rosdakarya.

Mudhofir. 1999, Teknologi Instruksional. Bandung: PT. Remaja Rosdakarya.

Muchlis R. Luddin, dkk. 2016. Pedoman Akademik 2016/2017 : Fakultas Ilmu Pendidikan UNJ, Universitas Negeri Jakarta

Onong Uchjana Effendy. 2012. Ilmu Komunikasi : Teori dan Praktek, Jakarta : Rosda

Pawit. 2010. Penelusuran Informasi, Jakarta : Kencana

Pratiwi, M. E., Nursetyo, K. I., \& Wirasti, R. M. K. (2018). Pengembangan Panduan Mendesain Konten E-Learning pada
Platform Totara. Jurnal Pembelajaran Inovatif, $\quad$ 33-42. https://doi.org/10.21009/JPI.012.05

Stevel D Tripp and Barbara Bichelmeyer. 1990. Rapid PrototypingI : An Alternative Instructional Design Strategy.

Sutarto. 2015. Dasar - Dasar Organisasi. Gadjah Mada University Press : Yogyakarta

Tripp, Steven and Bichelmeyer, Barbara. (1990) Rapid prototyping: An alternative instructional design strategy. Educational Technology Research and Development. Di akses pada

https://www.researchgate.net/public ation/225344439_Rapid_Prototyping _an_Alternative_Instructional_Desig n_Strategy Hari Selasa, 10 September 2019 pukul 18.50 WIB

Vincent Bayu Tapa Brata. 2007. Videografi dan Sinematografi Praktis, Jakarta: PT Elek Media Komputindo

\section{Peraturan dan Undang-undang}

Litbang dan Iptek. Sistem Nasional, Undangundang No.18 Tahun 2002

http://www.comp.dit.ie/dgordon/courses/ilt/ ilt0004/rapidprototypinganalternativ einstructionaldesign.pdf diakses pada 24 Juli 2019 pukul 11.08

http://www.hastac.org/files/ujch_a_614881. Pada 5 September 2019, Pukul 21.00

https://kbbi.web.id/

https://www.maxmanroe.com/vid/teknologi/ mobile-app/pengertian-ebook.html pada tanggal 3 Juli 2019, pukul 12.22

https://www.tckpublishing.com/what-is-anebook/ pada tanggal 3 Juli 2019, pukul 12.38 